\title{
NO news is good news
}

Shortly after the development of cardiopulmonary bypass in the 1960 s serious pulmonary and extrapulmonary sequelae of the technique were identified. ${ }^{12} \mathrm{~A}$ wide range of morbidity and even mortality was identified, the incidence of which varied according to the specific bypass methods and artificial materials employed. ${ }^{34}$

Cardiopulmonary bypass causes changes in recipient immunoreactivity, with activation of the complement cascade and an acute phase response. ${ }^{5}$ This may trigger the release of systemic proinflammatory mediators and cytokines synthesised from mononuclear cells, which produce profound humoral and cellular effects resulting in widespread endothelial damage. ${ }^{5}$ In adults, acute lung injury or acute respiratory distress syndrome (ARDS) may represent the pulmonary manifestation of this panendothelial insult. ${ }^{6}$ ARDS constitutes the commonest form of organ dysfunction in those who develop multiple organ system failure. A spectrum of lung injury characterised by increasing alveolar capillary permeability is demonstrable in all patients undergoing cardiopulmonary bypass, ${ }^{5} 1-2 \%$ of whom develop ARDS. ${ }^{7}$

The role of nitric oxide (NO) in modulating systemic inflammatory responses is increasingly recognised. ${ }^{89}$ Endogenous NO is a highly reactive, ephemeral, free-radical molecule synthesised from L-arginine by nitric oxide synthase (NOS). Several isoforms of this enzyme are known to exist, two of which are active in vascular tissues.

In arterial and arteriolar endothelium NO is synthesised by a constitutive, membrane bound, calcium dependent isoform (cNOS) which, in health, maintains basal vasodilator tone and contributes to endothelial thromboresistance by preventing platelet adhesion to the vessel wall. Platelets may also produce NO independently of the endothelium and this inhibits platelet activation. ${ }^{8}$

Immunostimulation may result in the de novo synthesis and calcium independent release of $\mathrm{NO}$ from macrophages via an inducible isoform of nitric oxide synthase (iNOS) located in the cytosol. NO is known to be cytotoxic and may be important in host defence. Unregulated NO release, however, may be responsible for the vascular leakage and tissue damage seen in some inflammatory conditions. ${ }^{10}$ Induction can be prevented by corticosteroids and inhibitors of protein synthesis and both selective and nonselective inhibitors of NOS activity have been described. ${ }^{11}$

The role of NO in regulating flow in the low pressure system of the lung is less clear. NO attenuates the vascular response of hypoxic pulmonary vasoconstriction in animal models. ${ }^{12}$ In vivo administration of exogenous inhaled NO produces selective and rapidly reversible pulmonary vasodilatation in patients with pulmonary hypertension ${ }^{13}$ but, in the absence of hypoxia, has no effect on lung haemodynamics in normal human volunteers. ${ }^{14}$ In patients with acute lung injury inhaled NO improves ventilationperfusion matching ${ }^{15}$ and may paradoxically limit increases in alveolar capillary permeability in experimental models. ${ }^{16}$

In this issue of Thorax (pages 403-404) Delgado and colleagues describe the presence of a calcium independent isoform of NO synthase isolated in lung biopsy specimens taken from patients before and after cardiopulmonary bypass. ${ }^{17}$ Although limited by sample size and the paucity of paired data, a significant increase in iNOS activity was seen after bypass in previously normal human lungs. The cellular origin of the enzyme is unknown. It is not surprising that a basal level of iNOS activity was identified as both cNOS and iNOS type isoforms have been identified in normal human lungs and appear to be compartmentalised. ${ }^{18}$ An enzyme, indistinguishable from iNOS, is located in the epithelium of airways and may have a physiological role in the regulation of bronchial tone. However, the absolute increase in iNOS activity observed after the bypass cannot be attributed to this alone. It is possible that the phenomenon observed by Delgado et al is a result of the pulmonary sequestration of activated neutrophils known to occur following cardiopulmonary bypass. ${ }^{19}$

The large increase in iNOS activity detectable after cardiopulmonary bypass, albeit only in three patients, is interesting because it implies an unusually rapid rate of iNOS induction. A similar time course has been observed in animal models of sepsis, but has not been seen in man. ${ }^{20}$

Although assays for cNOS and iNOS were made in the supernatant of biopsy specimens, the constitutive isoform is attached to the endothelial membrane and the amount that would remain in the particulate fraction after centrifugation is uncertain. It is therefore not possible to characterise the relative balance of $\mathrm{cNOS}$ and iNOS. It may be that the ratio of different isoforms will prove to be important in determining the precise role of NO in pulmonary vascular regulation.

If proinflammatory mediators cause endothelial injury, obviating their effects becomes an attractive therapeutic option. Attempts at modulating the immune response to cardiopulmonary bypass with corticosteroids, neutrophil modifiers, free radical scavengers, and specific monoclonal antibodies have been tried with disappointing results. ${ }^{21}$ Nevertheless, the recognition that iNOS is a potential progenitor of microvascular pathology may lead, inappropriately, to the indiscriminate use of NOS inhibitors. It is not known whether $\mathrm{NO}$ has a protective role in the context of acute lung injury. A number of potential disadvantages of wholesale inhibition of NOS exist, ${ }^{11}$ including impaired immunity, uncontrolled coagulation, and microvascular effects leading to systemic tissue hypoxia and increased alveolar capillary permeability. The role of inhibitors in modifying NO release and possible adverse effects in vivo need to be elucidated. Analogues of Larginine have been used in small numbers of patients with septic shock. Some improvements in haemodynamic indices were recorded without major side effects. ${ }^{2223} \mathrm{Se}-$ lectivity for iNOS theoretically offers a number of advantages over generalised NOS inhibition but no clinical data are, as yet, available to support this.

Delgado et al have provided pilot data that warrant further investigation. They show an apparent increase in iNOS activity after cardiopulmonary bypass which needs to be confirmed. The cellular origin and role of this isoform in the lung needs further characterisation. If it is established that the systemic and pulmonary vascular effects of increased iNOS activity adversely influence morbidity and survival, an area of potential therapeutic intervention has been identified. Any envisaged trial should address the problems of adverse effects and specificity. In view of the rapid induction of iNOS, the timing of any intervention may be crucial. Only after the results of such studies are 
known will it be possible to comment on the true significance of this report.

MS is supported by the Garfield Weston Trust.

Reprint requests to: Dr T W Evans.

Unit of Critical Care,

National Heart and Lung Institute,

MARK SAIR

London SW3 6LY, UK

1 Kirklin JW, Donald DE, Harshburger HG, Hetzel PS, Patrick RT, Swan $\mathrm{HJC}$, et al. Studies in extracorporeal circulation. Applicability of Gibbontype pump oxygenator to human intracardiac surgery: 40 cases. Ann Surg 1956;144:2-8.

2 Kirklin JW. Pulmonary dysfunction after open heart surgery. Med Clin North Am 1964;48:1063-8.

3 Moat N, Shore DS, Evans TW. Organ dysfunction and cardiopulmonary bypass: the role of complement and complement regulatory proteins. Surgery 1993; 7:S63-73.

4 Macnaughton PD, Braude S, Hunter DN, Denison DM, Evans TW Changes in lung function and pulmonary microvascular permeability after cardiopulmonary bypass. Crit Care Med 1992;20:1289-94

5 Kirklin JK, Westaby S, Blackstone EH, Kirklin JW, Chenoweth DE, Pacifico $\mathrm{AD}$. Complement and the damaging effects of cardiopulmonary bypass. F Thorac Cardiovasc Surg 1983;86:845-57.

6 Brigham KL. Mechanisms of lung injury. Eur Respir Rev 1992;2:16-8.

7 Fowler AA, Hamman RF, Good JT, Benson KN, Baird M, Eberle DJ, et al. Adult respiratory distress syndrome: risk with common dispositions. ann Intern Med 1983;98:593-7.

8 Moncada S, Palmer RMJ, Higgs EA. Nitric oxide: physiology, pathophysiology and pharmacology. Pharmacol Rev 1991;43:109-42.

9 Moncada S, Higgs A. Mechanisms of disease: the L-arginine-nitric oxide pathway. $N$ Engl $\mathcal{Y}$ Med 1993;329:2002-12.

10 Curzen NP, Griffiths MJD, Evans TW. Role of the endothelium in modulating the vascular response to sepsis. Clin Sci 1994;86:359-74.
11 Griffiths MJD, Curzen NP, Sair M, Evans TW. Nitric oxide synthase inhibitors in septic shock: theoretical considerations. Clin Intensive Care 1994;5:29-36.

12 Liu SF, Crawley DE, Barnes PJ, Evans TW. Endothelial derived relaxing factor inhibits hypoxic pulmonary vasoconstriction in rats. Am Rev Respir Dis 1991;143:32.

13 Pepke-Zaba J, Higenbottam TW, Dinh-Xuan AT, Stone D, Wallwork J. Inhaled nitric oxide as a cause of selective pulmonary vasodilatation in pulmonary hypertension. Lancet 1991;338:1173-4.

14 Frostell CE, Blomqvist $H$, Hedenstierna G, Lundberg J, Zapol WM. Inhaled nitric oxide selectively reverses human hypoxic pulmonary vasoconstriction nitric oxide selectively reverses human hypoxic pulmonary vasoconstriction

15 Rossaint R, Falke KJ, Lopez F, Slama K, Pison U, Zapal WM. Inhaled ?

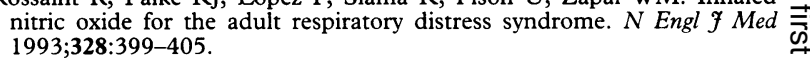

16 Kavanagh BP, Mouchawar A, Goldsmith J, Pearl RG. Effects of inhaled 7 $\mathrm{NO}$ and inhibition of endogenous NO synthesis in oxidant-induced acute lung injury. F Appl Physiol 1994;76:1324-9.

17 Delgado $R$, Rojas A, Glaria LA, Torres M, Duarte F, Shill R, et al. $\frac{\omega}{D}$ $\mathrm{Ca}^{2+}$-independent nitric oxide synthase activity in human lung after $\mathbb{D}$

18 Kobzik L, Bredt DS, Lowenstein CJ, Drazen J, Gaston B, Sugarbaker D, ஹ et al. Nitric oxide synthase in human and rat lung: immunocytochemical and histochemical localization. Am $\mathcal{F}$ Respir Cell Mol Biol 1993;9:371-7.

19 Braude S, Nolop KB, Flemming JS, Krausz T, Taylor KM, Royston D. Increased pulmonary transvascular protein flux after canine cardiopulmonary bypass. Association with lung neutrophil sequestration and $\vec{W}$ tissue peroxidation. Am Rev Respir Dis 1986;134:867-72.

20 Szabo C, Mitchell JA, Thiemermann C, Vane JR. Nitric oxide mediated hyporeactivity to adrenaline precedes the induction of nitric oxide synthase in endotoxin shock. Br $\mathcal{F}$ Pharmacol 1993;108:786-92.

21 Butler J, Rocker GM, Westaby S. Inflammatory response to cardiopulmonary bypass. Ann Thorac Surg 1993;55:552-9.

22 Petros A, Lamb G, Leone A, Moncada S, Bennett D, Vallance P. Effects of a nitric oxide synthase inhibitor in humans with septic shock. Cardiovasc $\omega$ Res 1994;28:34-9.

23 Lorente JA, Landin L, de Pablo R, Renes E, Liste D. L-arginine pathway in the sepsis syndrome Crit Care Med 1993;21:1287-95. 